\title{
Developmental programming of vascular dysfunction by prenatal and postnatal zinc deficiency in male and female rats ${ }^{2 / 3}$
}

\author{
Facundo Mendes Garrido Abregúa ${ }^{\mathrm{a}, \mathrm{b}}$, María Natalia Gobetto ${ }^{\mathrm{a}, \mathrm{b}}$, Lorena Vanesa Juriol ${ }^{\mathrm{a}, \mathrm{b}}$, Carolina Caniffi ${ }^{\mathrm{a}, \mathrm{b}}$, \\ Rosana Elesgaray ${ }^{\mathrm{a}, \mathrm{b}}$, Analía Lorena Tomat ${ }^{\mathrm{a}, \mathrm{b}, *}$, Cristina Arranz ${ }^{\mathrm{a}, \mathrm{b}}$ \\ a Universidad de Buenos Aires, Facultad de Farmacia y Bioquímica, Cátedra de Fisiología, Buenos Aires, Argentina \\ ${ }^{\mathrm{b}}$ CONICET, Universidad de Buenos Aires Instituto de la Química y Metabolismo del Fármaco (IQUIMEFA), Buenos Aires, Argentina
}

Received 12 October 2017; received in revised form 7 December 2017; accepted 17 January 2018

\begin{abstract}
Micronutrient malnutrition during intrauterine and postnatal growth may program cardiovascular diseases in adulthood. We examined whether moderate zinc restriction in male and female rats throughout fetal life, lactation and/or postweaning growth induces alterations that can predispose to the onset of vascular dysfunction in adulthood. Female Wistar rats were fed low- or control zinc diets from pregnancy to offspring weaning. After weaning, offspring were fed either a low- or a control zinc diet until 81 days. We evaluated systolic blood pressure (SBP), thoracic aorta morphology, nitric oxide (NO) system and vascular reactivity in 6- and/or 81-day-old offspring. At day 6, zinc-deficient male and female offspring showed a decrease in aortic NO synthase (NOS) activity accompanied by an increase in oxidative stress. Zinc-deficient 81-day-old male rats exhibited an increase in collagen deposition in tunica media, as well as lower activity of endothelial NOS (eNOS) that could not be reversed with an adequate zinc diet during postweaning life. Zinc deficiency programmed a reduction in eNOS protein expression and higher SBP only in males. Adult zinc-deficient rats of both sexes showed reduced vasodilator response dependent on eNOS activity and impaired aortic vasoconstrictor response to angiotensin-II associated with alterations in intracellular calcium mobilization. Female rats were less sensitive to the effects of zinc deficiency and exhibited higher eNOS activity and/or expression than males, without alterations in SBP or aortic histology. This work strengthens the importance of a balanced intake of micronutrients during perinatal growth to ensure adequate vascular function in adult life.
\end{abstract}

(c) 2018 Elsevier Inc. All rights reserved.

Keywords: Developmental programming; Zinc deficiency; Vascular function; Nitric oxide; Sex differences

\section{Introduction}

Micronutrient malnutrition has been recognized as a growing public health problem affecting an estimated 2 billion people worldwide who live on an unbalanced diet [1]. The most common micronutrient deficiencies exist for vitamin $\mathrm{A}$, folate, iron, zinc and iodine. Zinc deficiency was originally thought to be of rare occurrence, but it is now estimated that $17.3 \%$ of the world's population has inadequate zinc intake [2].

Epidemiological and experimental studies demonstrate a link between adverse intrauterine environment and increased risk of cardiovascular, renal and metabolic diseases in adulthood [3,4], and

\footnotetext{
t Grants: This work was supported by Universidad de Buenos Aires (2016-2018: 20020150200204BA; 2014/2017: 20020130100026BA) and Consejo Nacional de Investigaciones Científicas y Técnicas (2012-2015: PIP11220110100581; 2015-2017: 11220150100413CO).

* Corresponding author at: Cátedra de Fisiología, Facultad de Farmacia y Bioquímica, Universidad de Buenos Aires, IQUIMEFA-CONICET, Junín 956, CP 1113, Ciudad Autónoma de Buenos Aires, Argentina. Tel.: +54 11 52874708 .
}

E-mail address: atomat@ffyb.uba.ar (A.L. Tomat). this programming response to fetal injuries can differ between male and female offspring $[5,6]$. Therefore, moderate zinc restriction during pregnancy could be a nutritional insult to fetal and postnatal development [7].

Zinc is an essential micronutrient involved in vascular function and structure since it can modulate closely interrelated pathways, like nitric oxide (NO) production and oxidative stress. Zinc acts as an antioxidant inducing the generation of metallothioneins and binding to the sulfhydryl groups of biomolecules, thus protecting them from oxidation. It also increases the activation of antioxidant systems, decreases the activity of oxidant-promoting enzymes such as NADPH oxidase and inhibits lipid peroxidation [8-10]. Moreover, a zincdependent enzyme crucial to the vascular system is NO synthase (NOS). The NOS family consists of three isoforms: neuronal (nNOS), endothelial (eNOS) and inducible (iNOS). These enzymes catalyze the synthesis of $\mathrm{NO}$ and L-citrulline from L-arginine in the presence of $\mathrm{NADPH}$ and oxygen. It is well documented that NO production by eNOS inhibits endothelial cell apoptosis, leukocyte adhesion and platelet aggregation, and produces vascular smooth muscle relaxation and inhibition of its proliferation through paracrine action [11-14]. NOS contains a zinc thiolate $\left(\mathrm{ZnS}_{4}\right)$ cluster that plays an essential role in the catalytic activity of this enzyme by maintaining stability of the 
dimer interface and integrity of the tetrahydrobiopterin binding site $[15,16]$. Molecular dynamics studies suggest that the disruption of the zinc thiolate cluster would lead to a decoupling of the enzyme which would produce superoxide anion instead of generating NO [17].

In previous studies, we showed that dietary zinc restriction during prenatal and postnatal growth induces an increase in systolic blood pressure (SBP) and impairs renal function in adult male rats. These alterations were associated with an increase in renal oxidative stress and lower renal and vascular NOS activity [18-21]. In addition, we demonstrated that this nutritional injury alters cardiac development, evidenced by a reduction in myocyte size and in left ventricle (LV) wall thicknesses, as well as by decreased contractility of the LV in males in adult life. Moreover, zinc-deficient males showed hypertrophic remodeling of coronary arteries architecture associated with this chronic increase in arterial blood pressure. These cardiac alterations were related to changes in apoptosis, inflammatory cytokines, growth factors expression, oxidative stress state and NO system. On the other hand, females would be less sensitive to this micronutrient deficiency since they exhibited normal levels of SBP and no significant structural or functional cardiac alterations [22,23].

As a consequence of fetal programming, alterations in vascular function and morphology may be induced, thereby increasing the risk of cardiovascular disease in adulthood. Several human studies have shown the relationship between low birth weight and endothelial dysfunction in children [24,25] and young adults [26]. Moreover, animal models of fetal programming have shown that protein and caloric restriction during gestation induces intima-media thickness remodeling and changes in the composition of the extracellular matrix of aorta and mesenteric arteries [27].

Regarding endothelial function, impaired endothelium-dependent vasodilation has been reported in aorta, carotid and mesenteric arteries in offspring of dams following protein restriction, caloric restriction or hypoxia during pregnancy. In addition, male offspring with intrauterine growth restriction showed a more pronounced reduction in vascular relaxation than female offspring [28-30].

In the light of existing findings, we hypothesized that moderate zinc restriction in male and female rats throughout fetal life, lactation and/or postweaning growth induces alterations in vascular morphology and results in vascular disturbances in NO system and oxidative stress that can, in turn, predispose to the onset of vascular dysfunction in adult life. We further hypothesized that normal zinc-containing diet after weaning could not completely reverse the detrimental effects of earlier micronutrient imbalance on the vascular tissue.

To address this hypothesis, the objective of this study was to evaluate morphology, function, oxidative stress and NO system activity in thoracic aorta of male and female 6- and/or 81-day-old rats exposed to zinc deficiency during fetal life, lactation and/or postnatal growth.

\section{Materials and methods}

\subsection{Animals and study design}

Female Wistar rats weighing $280 \pm 10 \mathrm{~g}$ obtained from the breeding laboratories of the Facultad de Farmacia y Bioquímica, Universidad de Buenos Aires, Argentina, were mated by exposure to Wistar males for 1 week. Immediately afterwards, female rats were randomly fed either a moderately zinc-deficient diet ( $\mathrm{L}, 8 \mathrm{ppm}, n=17$ ) or a control zinc diet (C, $30 \mathrm{ppm}, n=11)$ during the pregnancy and lactation periods. Eight rat pups remained with each mother until 6 or 21 days of life (weaning) by random culling of pups at birth and retaining a 1:1 male-to-female ratio. Experimental groups at 6 days were as follows: male $(\mathrm{m})$ offspring of $\mathrm{C}$ mothers ( $\mathrm{Cm}$ group, $n=18)$, female (f) offspring of $C$ mothers (Cf group, $n=18$ ), male offspring of L mothers (Lm group, $n=18$ ) and female offspring of L mothers (Lf group, $n=18$ ). After weaning, male and female offspring of L mothers were fed either a low- ( $8 \mathrm{ppm}$; Llm and Llf groups, $n=24$ ) or a control (30 ppm; Lcm and Lcf groups, $n=24$ ) zinc diet for 60 days, and male and female offspring of $\mathrm{C}$ mothers were fed a control zinc diet (30 ppm; $\mathrm{Ccm}$ and $\mathrm{Ccf}$ groups, $n=24$ ) (Fig. 1)

Both diets had all the necessary nutrients, except zinc content, to meet rat requirements for the pregnancy and lactation periods according to AIN-93 recommendations [31].
Animals were cared for according to Argentina's National Drug, Food and Medical Technology Administration Standards (Regulation 6344/96) and the Guide for the Care and Use of Laboratory Animals published by the US National Institutes of Health (NIH Publication No. 85-23, Revised 1996). Experimental procedures were approved by the ethics committee for the care and use of laboratory animals of Facultad de Farmacia y Bioquímica, Universidad de Buenos Aires, Argentina (Res. 3191).

Mothers and their offspring were housed in plastic cages in a humidity- and temperature-controlled environment with a 12-h light-dark cycle. Animals were allowed food and deionized water ad libitum.

SBP was measured indirectly in awake animals by the tail-cuff method (PowerLab $8 / 30$ and Lab Chart 6 Pro software, ADInstruments, Australia) at 81 days of life. Prior to measuring SBP, rats were warmed in a thermostated $\left(25^{\circ} \mathrm{C}\right)$ and quiet room for $40 \mathrm{~min}$. The blood pressure value for each rat was calculated as the average of six separate measurements at each session. The first value measured in each session was discarded. At 6 and 81 days of life, animals were weighed and euthanized by cervical decapitation. Blood was collected to determine serum zinc concentration using atomic absorption spectrophotometry (Varian Spectrophotometer Spectr AA-20, air acetylene flame, 0.5nm slit, wavelength of 213.9 nm; Perkin-Elmer, Norwalk, CT, USA) [19,32]. Immediately after obtaining a blood sample, the thoracic aorta artery was removed and placed in an ice-cold saline solution or in Krebs buffer. Aortic rings of 81-day-old rats were used immediately to perform vascular reactivity studies. In order to perform histological evaluation, aortas of a group of rats were fixed in $10 \%$ phosphate buffered formalin for $24 \mathrm{~h}$ and then transferred to $70 \%$ ethanol, trimmed and embedded in paraffin. Aortic tissue to be used in evaluation of NOS activity and oxidative stress was stored at $-80^{\circ} \mathrm{C}$. Right tibia length (TL) was measured as a growth parameter.

\subsection{Histological analysis of thoracic aorta}

Hematoxylin-eosin staining was performed in aortic sections ( $5 \mu \mathrm{m}$ thick) from 6and 81-day-old rats to obtain morphometric parameters: total cross-sectional vascular area (TVA, excluding adventitia), tunica media area (MA) and lumen area (LA). The external (EP) and the internal perimeters (IP) were measured. TVA was calculated as $\mathrm{EP} \times \mathrm{EP} / 4 \pi$. LA was estimated as IP $\times \mathrm{IP} / 4 \pi$. MA was calculated by subtracting LA from the corresponding TVA. In addition, MA/LA ratio was determined and expressed as $\left(\mu \mathrm{m}^{2}\right)$ $\left.\mu \mathrm{m}^{2}\right)^{*} 100[33,34]$.

In both 6- and 81-day-old rats, Picrosirius Red staining allowed us to measure perivascular collagen area (CA), expressed as the CA/LA ratio $\left(\left(\mu \mathrm{m}^{2} / \mu \mathrm{m}^{2}\right)^{*} 100\right)$ in $5-\mu \mathrm{m}$ thick aortic sections [23]. Collagen fibers in aortic tunica media of 81 -day-old rats were evaluated on a subjective scale ranging from 0 to 4 (0: very poor staining of collagen fibers, 1: poor, 2: moderate, 3: intense, 4: very intense). Fifteen images of each animal were analyzed in order to obtain the mean value. The evaluation was performed by two independent observers in a blinded manner [35].

The number of elastin fibers layers, normalized to media thickness, was measured in 5 - $\mu$ m-thick aortic sections of 81-day-old rats using Verhoeff-Van Gieson staining [36,37].

Histological studies were analyzed using an Olympus BX51 light microscope equipped with a digital camera (Qcolor 3 Olympus America) and connected to ImagePro Plus 4.5.1.29 software (Media Cybernetics, LP, Silver Spring, MD, USA).

\subsection{Aortic oxidative stress}

Lipid oxidative damage in aortic slices was evaluated by measuring the formation of 2-thiobarbituric acid reactive substances (TBARS) as previously described $[22,38]$. Aortic slices from 6- and 81-day-old rats of both sexes were homogenized (Pro 200, Pro Scientific Inc., Oxford, CT, USA) in $30 \mathrm{mM}$ potassium phosphate buffer and $120 \mathrm{mM} \mathrm{KCl}$, $\mathrm{pH} 7.4(1 / 12 \mathrm{w} / \mathrm{v})$, and centrifuged at $2500 \mathrm{rpm}$ for $10 \mathrm{~min}$ at $4^{\circ} \mathrm{C}$. Supernatants were combined with butyl-hydroxy-toluene (4\%) and trichloroacetic acid (20\%) to precipitate proteins, centrifuged at $3000 \mathrm{rpm}$ for $10 \mathrm{~min}$ at room temperature and incubated with thiobarbituric acid $(0.7 \%)$ for $1 \mathrm{~h}$ at $100^{\circ} \mathrm{C}$. Absorbance was measured at $532 \mathrm{~nm}$. TBARS levels were calculated using a 1,1,3,3-tetramethoxypropane standard curve and were expressed as malondialdehyde content normalized to total homogenate protein content measured by the Bradford method.

Superoxide anion production was measured using the lucigenin-derived chemiluminescence method as previously described [39]. Aortic slices from 6- and 81-day-old rats of both sexes were placed in a solution containing $50 \mathrm{mM} \mathrm{Na}_{3} \mathrm{PO}_{4}, 1 \mathrm{mM}$ EGTA, 150 $\mathrm{mM}$ sucrose and $20 \mu \mathrm{M}$ lucigenin, $\mathrm{pH} 7.4$, at $37^{\circ} \mathrm{C}$. NADPH $(250 \mu \mathrm{M})$ was added to the reaction media as substrate, and chemiluminescence was immediately measured at 5 -s intervals for $3 \mathrm{~min}$ in a Labsystems Luminoskan RS Microplate Reader (Labsystems, Ramsey, MN, USA). Average luminescence value was normalized by the dry weight of tissue and was expressed as arbitrary units (AU) per dry weight. This method was used as an indirect measurement of NADPH oxidase activity [40]. The specificity of the assay was confirmed by addition of the superoxide scavenger TEMPOL (20 mM).

\subsection{Aortic NOS activity}

Aortic NOS activity of male and female rats at 6 and 81 days of life was evaluated as previously described [22]. Aortic slices (2-3 mm thick) were incubated for $30 \mathrm{~min}$ at $37^{\circ} \mathrm{C}$ in Krebs solution with [14C] L-arginine $0.5 \mu \mathrm{Ci} / \mathrm{ml}$ (specific activity $360 \mathrm{mCi} / \mathrm{mmol}$; Perkin Elmer Life and Analytical Sciences, Boston, MA, USA). Tissue samples were homogenized in the stop solution (0.5 mM EGTA, 0.5 mM EDTA, 20mM HEPES, pH 5.5), 


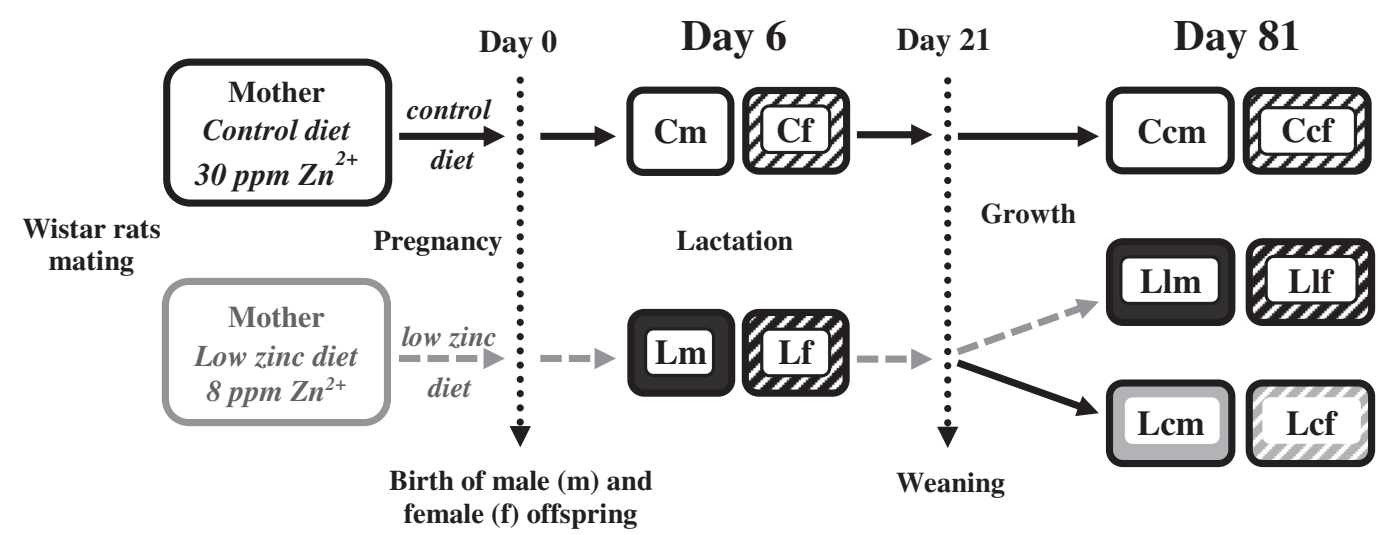

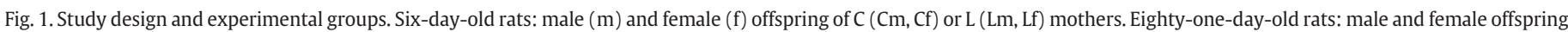
of $\mathrm{L}$ mothers fed a low- (Llm, Llf) or a control ( $\mathrm{Lcm}$, Lcf) zinc diet for 60 days after weaning, and male and female offspring of $\mathrm{C}$ mothers fed a control zinc diet (Ccm, Ccf).

and the homogenates were centrifuged at $12,000 \mathrm{~g}$ for $20 \mathrm{~min}$. The supernatants were applied to a 1-ml Dowex AG 50W-X8 column (Na+ form; Bio-Rad Laboratories, Hercules, CA, USA) and eluted with $2 \mathrm{ml}$ of distilled water, and the amount of $\left[{ }^{14} \mathrm{C}\right] \mathrm{L}-$ citrulline was determined with a liquid scintillation counter (Wallac 1414 WinSpectral, EG\&G Company, 215 Turku, Finland). NOS activity was expressed as picomoles of $\left[{ }^{14} \mathrm{C}\right]$ L-citrulline per gram of wet weight per minute. To determine activity of NOS isoforms in aortas of 81-day-old rats, tissue slices were previously incubated with $1 \mathrm{mM}$ aminoguanidine (AG, inducible NOS specific inhibitor), $10 \mathrm{mM}$ 7-nitroindazole (7-NI, neuronal NOS specific inhibitor), $1 \mu \mathrm{M}$ calmidazolium $(\mathrm{Cz}$, calcium-calmodulin antagonist) and $1 \mu \mathrm{M}$ L-nitro-arginine-methyl-ester (L-NAME, NOS nonspecific inhibitor) for $15 \mathrm{~min}$.

\subsection{Aortic eNOS and phosphorylated eNOS protein expression by Western blot analysis}

Aortic eNOS and phosphorylated eNOS at $\operatorname{Ser}^{1177}$ (pSer ${ }^{1177}$-eNOS) protein expression was evaluated by Western blot analysis as previously described [41]. Aortas of 81-day-old male and female rats were homogenized and centrifuged. Equal amounts of protein ( $50 \mu \mathrm{g}$ protein/lane) were separated by electrophoresis in 7.5\% SDS-polyacrylamide gels, transferred to a nitrocellulose membrane (Amersham GE Healthcare, United Kingdom) and incubated with rabbit polyclonal anti-eNOS (BD Transduction Laboratories), anti$\mathrm{pSer}^{1177}$-eNOS (Cell Signaling, Danvers, MA, USA) and anti- $\beta$-actin (Sigma-Aldrich, San Luis, MO, USA) antibodies diluted $1 / 1000,1 / 1000$ and $1 / 2000$ in $1 \%$ bovine serum albumin, respectively. To evaluate $\beta$-actin protein expression, membranes were then incubated with a horseradish-peroxidase-conjugated goat anti-rabbit secondary antibody diluted 1 / 3000 (Bio-Rad, Hercules, CA, USA). eNOS and pSer $^{1177}$-eNOS membranes were incubated with a biotinylated anti-rabbit secondary antibody and then with a horseradishperoxidase-streptavidin complex solution (Vectastain Universal Quick HRP kit, Vector laboratories, Burlingame, CA USA).

Samples were detected by chemiluminescence using ECL Prime Western Blotting Detection Reagent (Amersham, GE Healthcare, United Kingdom). Relative protein expression was quantified from the autoradiograph using a scanner (HP Photosmart C3180) and ImageJ software (National Institutes of Health). Optical density (OD) of eNOS was normalized to $\beta$-actin OD, $\mathrm{pSer}^{1177}$-eNOS OD was normalized to eNOS OD, and the fold change was calculated versus $\mathrm{Ccm}$ values. All experiments were performed in triplicate.

\subsection{Vascular reactivity of aortic rings}

After decapitation, thoracic aortas of 81-day-old male and female rats were immediately removed. The aortas were dissected free of fat and periadventitial tissue and cut into 3-4-mm-long ring segments. Rings were mounted in 10-ml organ baths filled with oxygenated Krebs buffer at $37^{\circ} \mathrm{C} \pm 0.5^{\circ} \mathrm{C}\left(95 \% \mathrm{O}_{2}, 5 \% \mathrm{CO}_{2}\right)$. Composition of Krebs buffer in mM: NaCl, 118; KCl, 4.7; $\mathrm{NaHCO}_{3}, 25 ; \mathrm{NaH}_{2} \mathrm{PO}_{4}, 1.13 ; \mathrm{CaCl}_{2}, 2.55 ; \mathrm{MgCl}_{2}$, 1.15; D-glucose, 11.1; EDTA, 0.004; ascorbic acid, 0.11; pH 7.4. Isometric tension (g) was measured using an isometric force transducer (TRI201, PanLab, Spain) connected to a PowerLab 8/30 system with LabChart 6.0 recording software (AD Instruments, Australia). After an equilibration period of $60 \mathrm{~min}$, each aortic ring was stretched to an optimal resting tension of $1 \mathrm{~g}$. A control stimulation with potassium-rich Krebs solution ( $\mathrm{KCl} 90 \mathrm{mM}$ ) was initially performed. Afterwards, rings were washed during a 30-min recuperation period. Isolated aortic rings were then stimulated with phenylephrine (Phe, $10^{-6} \mathrm{M}$ ) and relaxed with one dose of acetylcholine ( $\mathrm{ACh}, 10^{-3}$ $\mathrm{M}$ ) in order to verify endothelial viability. All rings were subsequently washed to bring aortic tension back to $1 \mathrm{~g}$ to perform relaxation or constriction protocols $[42,43]$.

\subsubsection{Relaxation responses to acetylcholine and sodium nitroprusside}

Aortic rings with intact endothelium were stimulated with increasing concentrations of $\mathrm{ACh}\left(10^{-10}\right.$ to $\left.10^{-3} \mathrm{M}\right)$ after constriction with Phe $\left(10^{-6} \mathrm{M}\right)$. These experiments were performed in the presence or absence of L-NAME (10 mM, 30-min preincubation before Phe).

Further, some rings were treated by mechanical procedures to remove the endothelium layer before mounting in the organ bath. In endothelium-denuded rings, relaxation response to $\mathrm{ACh}\left(10^{-10}\right.$ to $\left.10^{-3} \mathrm{M}\right)$ or sodium nitroprusside (SNP, NO donor, $10^{-13}$ to $\left.10^{-5} \mathrm{M}\right)$ was evaluated after Phe $\left(10^{-6} \mathrm{M}\right)$ constriction. ACh or SNP response was expressed as a percentage of relaxation after Phe constriction [44].

\subsubsection{Constriction responses to angiotensin-II and caffeine}

Aortic rings with intact endothelium were stimulated with increasing concentrations of angiotensin-II (AngII, $10^{-10}$ to $10^{-7} \mathrm{M}$ ) [45].

Further, vasoconstrictor response to caffeine ( $25 \mathrm{mM}$, single dose) was evaluated in endothelium-denuded rings preincubated for $15 \mathrm{~min}$ with calcium-free Krebs solution (composition in mM: $\mathrm{NaCl}, 118 ; \mathrm{KCl}, 4.7 ; \mathrm{NaHCO}_{3}, 25 ; \mathrm{NaH}_{2} \mathrm{PO}_{4}, 1.13 ; \mathrm{MgCl}_{2}, 1.15$; Dglucose, 11.1; EGTA, 2; pH 7.4). The contractile tension to AngIl or caffeine was normalized by the maximum contraction elicited by the stimulation with $\mathrm{KCl} 90 \mathrm{mM}$ $[46]$.

\subsection{Statistical analysis}

Prism software (Graph Pad Prism 5.0, San Diego, CA, USA) was used for statistical analysis. Shapiro-Wilk test was used to check normal distribution. Normally distributed data values were expressed as mean \pm S.E.M. The mean and standard error values of the experimental groups were analyzed using a two-way analysis of variance (ANOVA). The tested factors were diet versus sex in both 6- and 81-day-old rats. If the diet $\times$ sex interaction was not significant, two-way ANOVA was performed followed by Bonferroni post hoc test for multiple comparisons of main effects. When the diet $\times$ sex interaction was significant, the simple effects were analyzed by Bonferroni post hoc test for multiple comparisons between groups of interest. Data obtained from a subjective scale (score) were expressed as median and range. Nonparametric Kruskal-Wallis test was performed followed by Dunn's test. A value of $P<.05$ was considered statistically significant.

Concentration-response curves to ACh, NPS and AngII were analyzed using a sigmoidal fit curve with variable slope to obtain maximal response (Emax) and $\mathrm{pEC}_{50}$ as a measure of potency $\left(-\log E C_{50}\right.$, where $\mathrm{EC}_{50}$ was the molar concentration required for $50 \%$ of the maximal effect). Emax to a single dose of caffeine was normalized by the maximum contraction elicited by the stimulation with $\mathrm{KCl} 90 \mathrm{mM}$.

Table 1

Body weight, tibia length and serum zinc concentration at 6 days of life

\begin{tabular}{lllll}
\hline & $\mathrm{Cm}$ & Lm & Cf & Lf \\
\hline Body weight $(\mathrm{g})$ & $13.2 \pm 0.1$ & $12.1 \pm 0.2^{*}$ & $12.5 \pm 0.2$ & $11.1 \pm 0.2 \dagger, \dagger$ \\
Tibia length $(\mathrm{mm})$ & $8.88 \pm 0.05$ & $8.91 \pm 0.09$ & $8.87 \pm 0.05$ & $8.75 \pm 0.07$ \\
Serum zinc concentration $(\mu \mathrm{g} / \mathrm{dl})$ & $173 \pm 5$ & $103 \pm 7^{*}$ & $131 \pm 7$ & $89 \pm 9 \dagger$ \\
\hline
\end{tabular}

${ }^{*} P<.01$ vs. $\mathrm{Cm} ; \ddagger P<.01$ vs. $\mathrm{Lm} ; \dagger P<.01$ vs. Cf. Values are expressed as mean \pm S.E.M.; $n=12$ per group. Data were analyzed using two-way ANOVA followed by Bonferroni post hoc test. 
Table 2

Body weight, tibia length, serum zinc concentration and SBP at 81 days of life

\begin{tabular}{|c|c|c|c|c|c|c|}
\hline & $\mathrm{Ccm}$ & Llm & $\mathrm{Lcm}$ & $\mathrm{Ccf}$ & Llf & Lcf \\
\hline Body weight (g) & $387 \pm 5$ & $315 \pm 9 *$ & $348 \pm 7^{*}+$ & $253 \pm 4^{*}$ & $216 \pm 4 \dagger, \ddagger$ & $220 \pm 5 \dagger, \S$ \\
\hline Tibia length $(\mathrm{cm})$ & $3.90 \pm 0.03$ & $3.64 \pm 0.03^{*}$ & $3.72 \pm 0.03^{*}$ & $3.54 \pm 0.02^{*}$ & $3.39 \pm 0.02 \dagger, \ddagger$ & $3.37 \pm 0.02 \dagger, \S$ \\
\hline Serum zinc concentration $(\mu \mathrm{g} / \mathrm{dl})$ & $160 \pm 9$ & $120 \pm 5^{*}, \S$ & $147 \pm 10$ & $158 \pm 6$ & $106 \pm 7 \dagger, \mathrm{a}$ & $150 \pm 6$ \\
\hline $\mathrm{SBP}(\mathrm{mmHg})$ & $126 \pm 1$ & $143 \pm 2^{*}$ & $146 \pm 2^{*}$ & $119 \pm 3$ & $120 \pm 4 \dagger$ & $125 \pm 3 \S$ \\
\hline
\end{tabular}

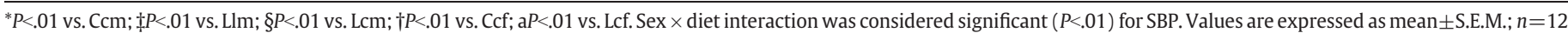
per group. Data were analyzed using two-way ANOVA followed by Bonferroni post hoc test.

\section{Results}

\subsection{Offspring body weight, TL, serum zinc and SBP}

At 6 days of life, Lm and Lf offspring exhibited lower body weight and serum zinc concentration compared with $\mathrm{Cm}$ and $\mathrm{Lm}$, respectively. There were no significant differences in TL among these groups (Table 1). At 81 days of life, Llm, Lcm, Llf and Lcf rats showed reduced body weight and TL compared with $\mathrm{Ccm}$ and $\mathrm{Ccf}$, respectively. These growth markers were higher in male than in female groups. Serum zinc concentration was decreased in Llm and Llf. Llm and Lcm rats showed an increase in SBP compared with $\mathrm{Ccm}$. However, no differences in SBP levels were observed among females (Table 2).

\subsection{Histological analysis of thoracic aorta}

Morphometric parameters were measured in aortic sections stained with hematoxylin-eosin or Picrosirius Red. No significant differences in MA/LA (Cm: 67 \pm 7, Lm: 60 \pm 7, Cf: $68 \pm 6$, Lf: $62 \pm 4$ ) or CA/LA (Cm: $20 \pm$ 2, Lm: $19 \pm 1$, Cf: $22 \pm 3$, Lf: $21 \pm 2$ ) ratios were found among 6-day-old offspring. In addition, zinc restriction did not induce changes in MA/LA or CA/LA ratios in aortas of 81-day-old rats (Table 3 ).

Elastin fibers were evaluated using Verhoeff-Van Gieson staining in aortas of 81-day-old rats of both sexes. There were no significant differences in the number of elastic fibers normalized to media thickness among the experimental groups (Table 3, Fig. 2). Collagen fibers in aortic tunica media of 81-day-old rats were analyzed using Picrosirius Red staining. Llm showed an increase in collagen fibers deposition in tunica media compared with $\mathrm{Ccm}$ (Table 3, Fig. 3), but no significant differences were observed among females.

\subsection{Aortic oxidative stress}

TBARS assay was performed to evaluate lipid oxidative damage in thoracic aorta. Six-day-old Lm and Lf offspring exhibited an increase in aortic levels of lipid peroxidation products compared with $\mathrm{Cm}$ and $\mathrm{Cf}$, respectively (Fig. 4A). However, there were no significant differences among 81-day-old experimental groups (Fig. 4B).

Aortic superoxide anion production induced by NADPH was measured at 6 and 81 days of life. Six-day-old $C$ rats showed reduced superoxide anion production compared with males. On the other hand, higher values were observed in Lf compared with Cf (Fig. 4C).
There were no significant differences in superoxide anion production induced by NADPH among 81-day-old experimental groups (Fig. 4D).

\subsection{Aortic NOS activity}

NOS activity was measured in thoracic aorta at 6 and 81 days of life. Six-day-old Lm and Lf offspring showed a decrease in basal NOS activity compared with $\mathrm{Cm}$ and $\mathrm{Cf}$, respectively (Fig. 5A). At 81 days of life, Llm, Llf, Lcm and Lcf offspring exhibited lower basal NOS activity than $\mathrm{Ccm}$ and $\mathrm{Ccf}$, respectively. Female groups showed higher basal NOS activity levels than males (\% increase in NOS activity vs. males: Ccf: 16\%; Llf: 17\%; Lcf: 26\%) (Fig. 5B). In 81-day-old experimental groups, basal NOS activity was blunted when L-NAME was previously added, thus verifying that the activity measured was specifically linked to NOS. In addition, basal NOS activity was abolished by using a calciumcalmodulin antagonist but not by using nNOS or iNOS inhibitors (Fig. 5C-D). These results suggest that the reduction in basal NOS activity in zincdeficient animals is mainly due to eNOS isoform.

\subsection{Aortic eNOS and $\mathrm{pSer}^{1177}$-eNOS protein expression}

Given the effects of zinc deficiency on eNOS activity in 81-day-old rats, we evaluated protein expression by Western blot analysis. Moreover, we determined eNOS phosphorylation at Ser ${ }^{1177}$ since it is one of the most important posttranslational modifications that activate this enzyme. Thoracic aortas of Llm and Lcm adult rats showed not only a decrease in eNOS activity but also reduced eNOS protein expression. However, there were no significant differences in eNOS protein expression in 81-day-old females. Consistent with the results for eNOS activity, Llf and Lcf presented higher levels of eNOS protein compared with Llm and Lcm, respectively (Fig. 6A). No significant differences were observed in $\mathrm{pSer}^{1177}$-eNOS levels among the experimental groups (Fig. 6B).

\subsection{Vascular reactivity of aortic rings}

The response to different vasoconstrictor and vasodilator agents was studied in isolated thoracic aortic rings of 81-day-old rats.

In order to assess whether alterations in endothelial NO production affect vascular function, we evaluated vasodilator response to ACh in aortic rings preconstricted with Phe. Compared with Cc, vasodilator maximal response to $\mathrm{ACh}$ was reduced in intact-endothelium rings from $\mathrm{Ll}$ and Lc groups of both sexes (Table 4, Fig. 7A-B). Preincubation with L-NAME or endothelium removal abolished vasorelaxation

Table 3

Morphometric parameters, elastin fibers and collagen deposition in aortas at 81 days of life

\begin{tabular}{|c|c|c|c|c|c|c|}
\hline & $\mathrm{Ccm}$ & Llm & Lcm & $\operatorname{Ccf}$ & Llf & Lcf \\
\hline $\mathrm{MA} / \mathrm{LA}$ & $23.4 \pm 0.6$ & $23.3 \pm 0.5$ & $23.8 \pm 0.6$ & $25.2 \pm 0.7$ & $25.1 \pm 0.5$ & $25.7 \pm 0.4$ \\
\hline $\mathrm{CA} / \mathrm{LA}$ & $22 \pm 1$ & $22 \pm 1$ & $20 \pm 1$ & $20 \pm 1$ & $21 \pm 1$ & $19 \pm 1$ \\
\hline Elastin fibers (layers/100- $\mu \mathrm{m}$ media thickness) & $8.9 \pm 0.5$ & $9.1 \pm 0.5$ & $9.1 \pm 0.6$ & $9.1 \pm 0.6$ & $9.0 \pm 0.4$ & $8.8 \pm 0.3$ \\
\hline Collagen fibers in tunica media (score) & $1.0(0.2 ; 2.1)$ & $3.0^{*}(1.7 ; 4.0)$ & $1.5(1.1 ; 2.1)$ & $1.5(1.0 ; 3.0)$ & $2.3(0.8 ; 3.0)$ & $1.8(1.2 ; 3.3)$ \\
\hline
\end{tabular}

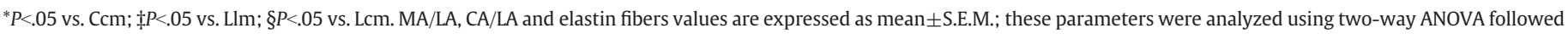

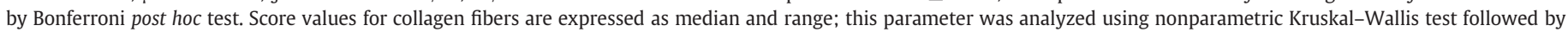
Dunn's test. $n=6$ per group. 

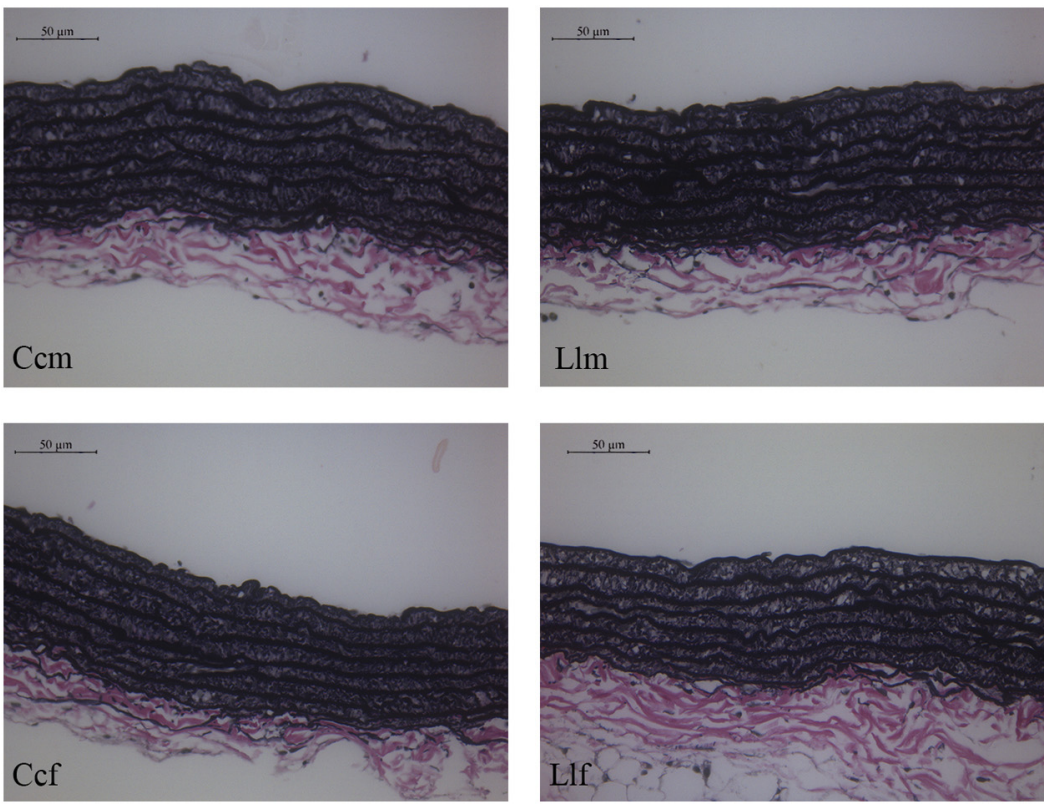

Fig. 2. Verhoeff-Van Gieson staining in thoracic aorta of 81 -day-old rats. Elastin fibers are stained black. All images are at the same magnification $(400 \times)$; scale bar $=50 \mu m$.

induced by ACh, confirming that the ACh vasodilator response is mediated by eNOS (Table 4). However, no significant differences in vasodilator response to the NO donor SNP were observed in endothelium-denuded rings (Table 4, Fig 7C-D).

We also evaluated whether zinc deficiency induces alterations in aortic constriction. In rings with intact endothelium, there were no changes in $\mathrm{KCl} 90 \mathrm{mM}$ maximal response (Ccm: 1.24 \pm 0.05 ; Llm: 1.20 \pm 0.05 ; Lcm: $1.28 \pm 0.06$; Ccf: $1.22 \pm 0.05$; Llf: $1.19 \pm 0.05$; Lcf: $1.10 \pm$ $0.05 \mathrm{~g} ; n=8$ per group). However, vasoconstrictor response to AngII was reduced in male and female $\mathrm{Ll}$ and $\mathrm{Lc}$ compared with $\mathrm{Cc}$ rats (Table 4, Fig 7E-F). In addition, $\mathrm{Ll}$ and Lc rats of both sexes exhibited alterations in intracellular calcium mobilization, showing decreased contractile maximal response to caffeine (Table 4).
No significant differences were observed in $\mathrm{pEC}_{50}$ values in $\mathrm{ACh}$, SNP or AngII protocols (Table 4).

\section{Discussion}

The results of the present study demonstrate that moderate zinc deficiency during critical periods of prenatal and postnatal development leads to permanent and long-term changes in aortic tissue. This in turn results in the programming of a lifelong alteration of the functional capacity of the vessels and predispose to CVD in adult life. Moreover, as in many developmental programming models, we found that male and female offspring exhibit different phenotypes in
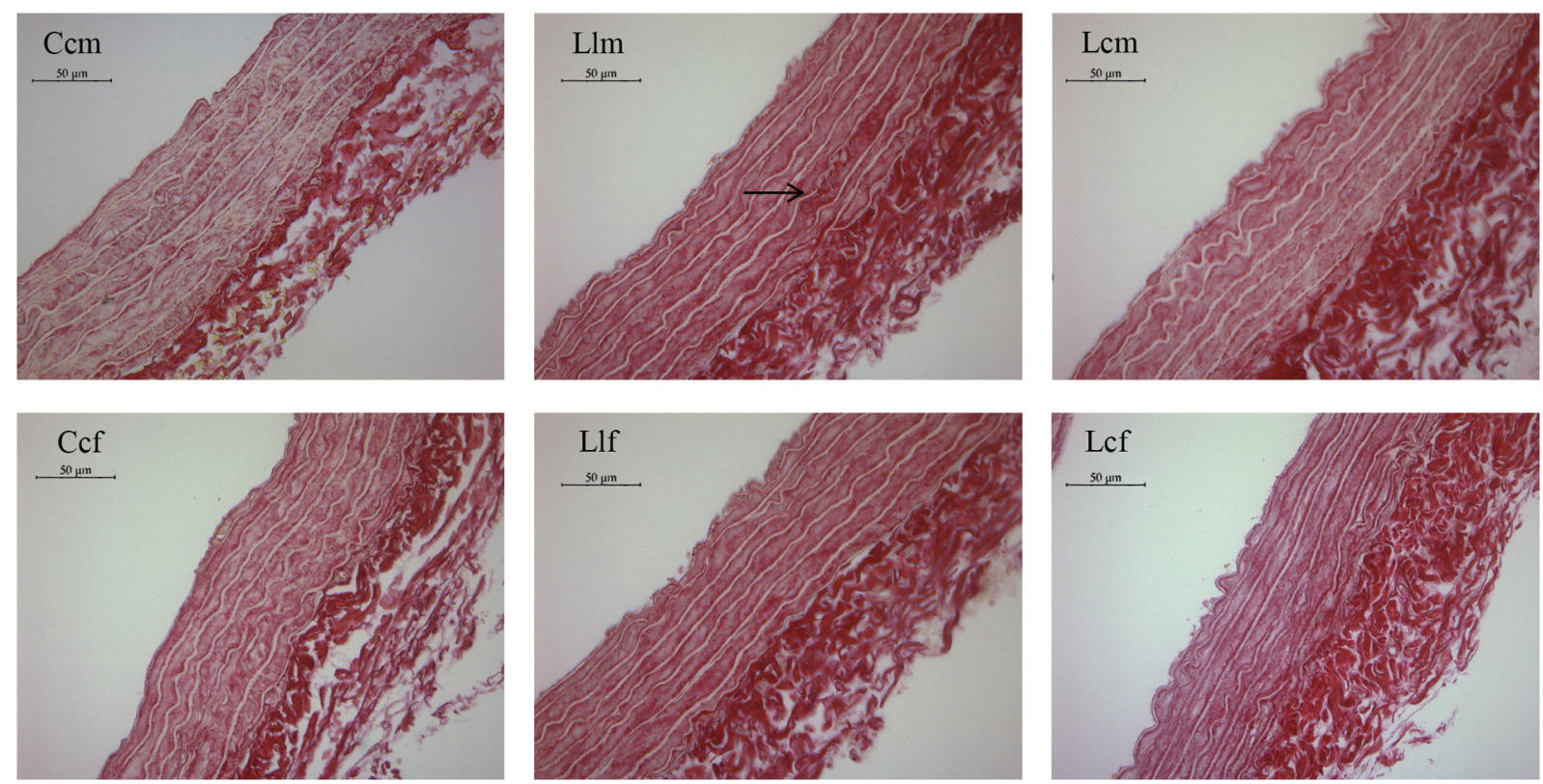

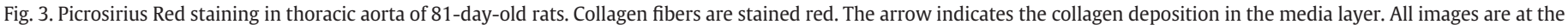
same magnification $(400 \times)$; scale bar $=50 \mu \mathrm{m}$. 
A

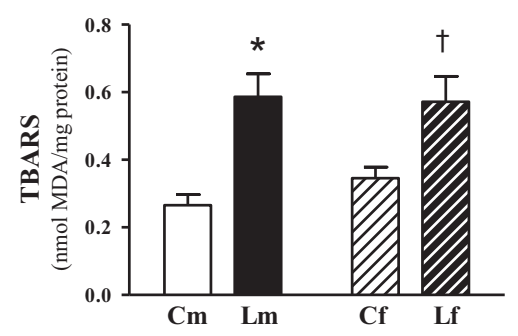

C

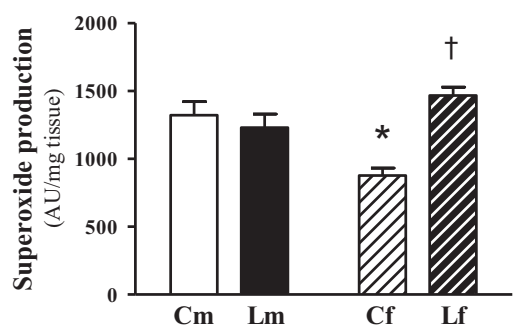

B

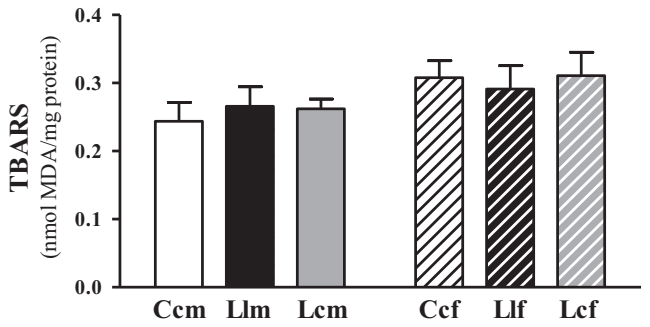

D

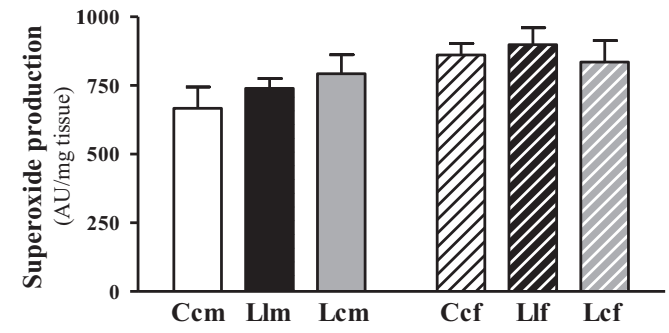

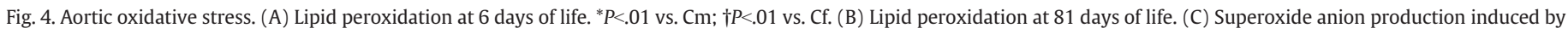

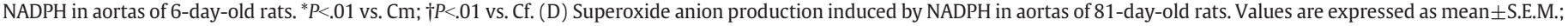
$n=6$ per group. Data were analyzed using two-way ANOVA followed by Bonferroni post hoc test.

A

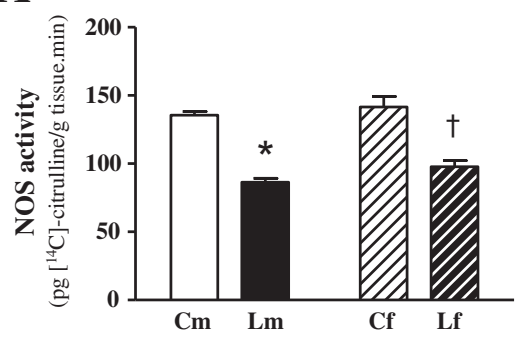

B

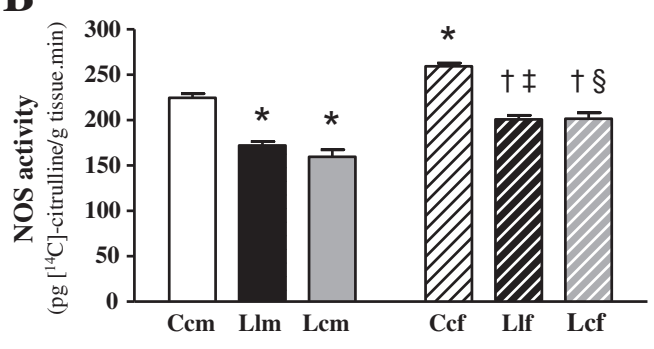

C

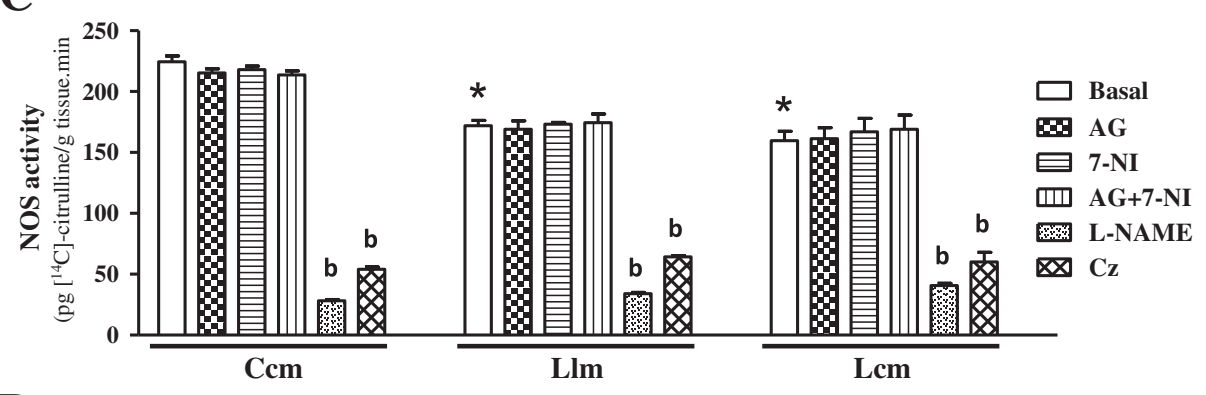

D

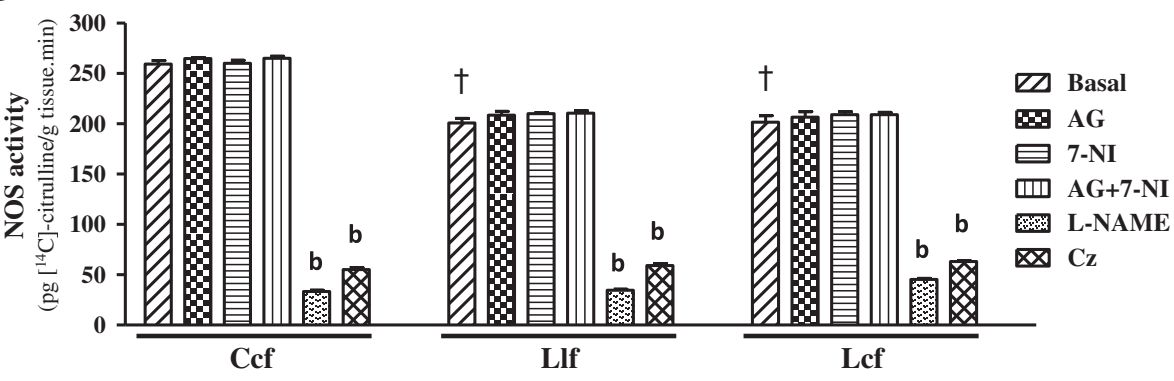

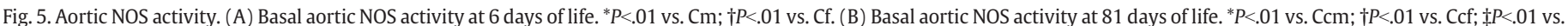

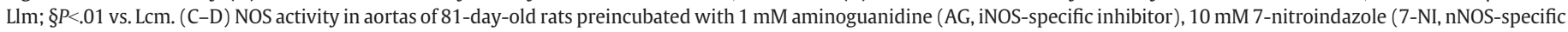

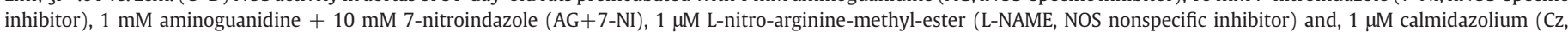

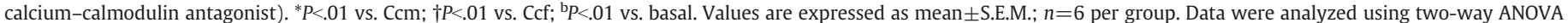
followed by Bonferroni post hoc test. 
A

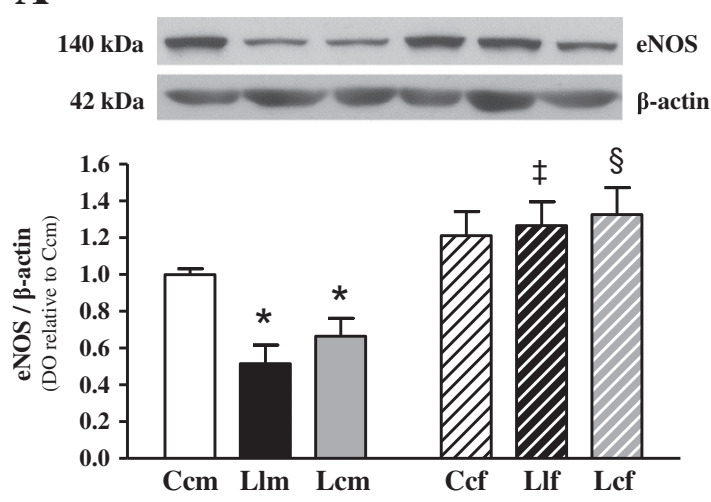

B
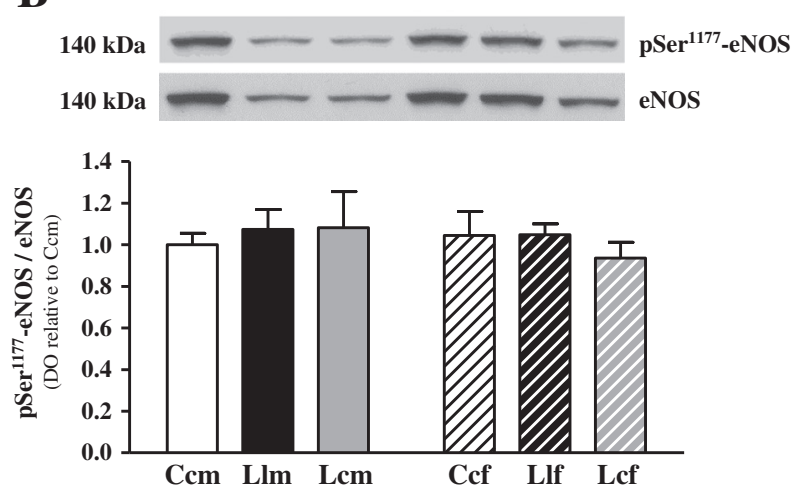

Fig. 6. Aortic eNOS (A) and pSer ${ }^{1177}$-eNOS (B) protein expression in 81-day-old rats. ${ }^{*} P<.05$ vs. Ccm; $\ddagger P<.05$ vs. Llm; $\S P<.05$ vs. Lcm. Values are expressed as mean \pm S.E.M.; $n=6$ per group. Data were analyzed using two-way ANOVA followed by Bonferroni post hoc test.

response to insults during critical periods of development, as well as differences in the severity of vascular alterations [5,29].

As in our previous studies, we observed that moderate zinc deficiency during prenatal and postnatal life induced a growth delay in male and female offspring and an increase in SBP only in adult males. In this regard, several studies have described that zinc can stimulate cell proliferation by up-regulating gene expression of the DNA synthesizing enzyme deoxythymidine kinase [47] and by stimulating synthesis of the growth hormone and insulin-like growth factors [48]. Moreover, the fact that an adequate zinc diet during postweaning life could normalize neither all growth markers in male and female offspring nor SBP in male rats highlights the importance of this micronutrient in determining cardiovascular risk factors. Further- more, our results are supported by human studies reporting an inverse correlation between the level of arterial pressure and serum and hair zinc concentration $[49,50]$. On the other hand, the sex differences observed in SBP in our model are consistent with findings across diverse developmental programming animal models showing that female offspring exhibit a protected status regardless of the species or specific fetal insult $[51,52]$.

Even though dietary zinc restriction induced growth delay, no alterations in aortic morphometric parameters were observed either in early postnatal or in adult life. Male and female offspring exposed to this micronutrient deficiency during different periods of growth showed similar MA/LA and CA/LA ratios and number of elastic fibers in the media layer as control animals. However, Llm showed an increase in collagen content in tunica media that could be an early sign of vascular remodeling associated with higher tensional stress due to the chronic increase in SBP [53]. This alteration was not observed in female rats.

Several studies have evidenced that NO plays integral roles in the vascular system by regulating vascular smooth muscle tone [11] and vascular development $[54,55]$. In the present study, zinc-deficient male and female offspring showed lower aortic NOS activity at early periods of postnatal life that persisted until adulthood. The decrease in NO system activity was observed even when these animals were fed an adequate zinc diet during postweaning life, suggesting that this fetal injury can program the functional capacity of the NO system in adulthood. In this regard, we have demonstrated that moderate zinc deficiency during fetal and postnatal growth induces similar effects in renal and cardiac NO systems $[18,21,22,56]$.

In the present study, we demonstrated that decreased NOS activity in aorta would be mainly associated with lower eNOS activity in adult male and female zinc-deficient rats. In adult Llm and Lcm rats, the decrease in aortic eNOS activity could be related to reduced eNOS protein expression but not to changes in the activation of eNOS regulated by Ser ${ }^{1177}$ phosphorylation. Meanwhile, Llf and Lcf showed a decrease in eNOS activity compared with Ccf that was not accompanied by alterations in eNOS protein expression or in Ser ${ }^{1177}$ phosphorylation. Several studies have demonstrated that aortic eNOS activity could be modulated by different posttranslational regulatory mechanisms, including alterations in (1) the dimeric enzyme structure; (2) subcellular localization; (3) interactions with caveolin and heat shock protein 90; (4) phosphorylation, dephosphorylation, S-nitrosylation and acetylation reactions; and (5) availability of L-arginine and co-factors (flavins, NADPH and tetrahydrobiopterin) $[17,57,58]$. Zinc restriction would affect tetrahydrobiopterin availability since this micronutrient is crucial for the activity of enzymes involved in its synthesis, such as GTP cyclohydrolase I and 6-pyruvoyl tetrahydropterin synthase [59,60]. Therefore, we postulate that disturbances in zinc homeostasis could affect posttranslational regulatory mechanisms leading to reduced NOS activity in a sexspecific manner, and these effects persist until adulthood.

Table 4

Response to different vasodilator or vasoconstrictor agents in aortic rings with intact endothelium (e+) or denuded endothelium (e-) at 81 days

\begin{tabular}{|c|c|c|c|c|c|c|c|}
\hline & & $\mathrm{Ccm}$ & Llm & $\mathrm{Lcm}$ & Ccf & Llf & Lcf \\
\hline \multirow[t]{2}{*}{$\mathrm{ACh}(\mathrm{e}+)$} & Emax & $92 \pm 2$ & $72 \pm 4^{*}$ & $77 \pm 4^{*}$ & $102 \pm 4$ & $86 \pm 5 \dagger, \ddagger$ & $80 \pm 4 \dagger$ \\
\hline & $\mathrm{pEC}_{50}$ & $8.0 \pm 0.2$ & $8.0 \pm 0.4$ & $7.6 \pm 0.3$ & $7.7 \pm 0.1$ & $7.3 \pm 0.3$ & $7.7 \pm 0.4$ \\
\hline ACh + L-NAME $(\mathrm{e}+)$ & Emax & $6 \pm 3$ & $4 \pm 3$ & $4 \pm 3$ & $5 \pm 3$ & $9 \pm 2$ & $8 \pm 2$ \\
\hline $\mathrm{ACh}(\mathrm{e}-)$ & Emax & $8 \pm 3$ & $8 \pm 2$ & $4 \pm 2$ & $11 \pm 3$ & $10 \pm 4$ & $9 \pm 4$ \\
\hline \multirow{2}{*}{$\mathrm{SNP}(\mathrm{e}-)$} & Emax & $109 \pm 2$ & $115 \pm 1$ & $114 \pm 2$ & $110 \pm 1$ & $110 \pm 2$ & $109 \pm 2$ \\
\hline & $\mathrm{pEC}_{50}$ & $10.2 \pm 0.1$ & $10.1 \pm 0.1$ & $10.2 \pm 0.1$ & $10.8 \pm 0.1$ & $11.1 \pm 0.3 \ddagger$ & $10.6 \pm 0.2$ \\
\hline \multirow{2}{*}{ AngII $(e+)$} & Emax & $31 \pm 3$ & $21 \pm 2^{*}$ & $23 \pm 2^{*}$ & $30 \pm 2$ & $19 \pm 2 \dagger$ & $18 \pm 3 \dagger$ \\
\hline & $\mathrm{pEC}_{50}$ & $7.7 \pm 0.3$ & $8.0 \pm 0.1$ & $7.9 \pm 0.1$ & $7.7 \pm 0.1$ & $8.1 \pm 0.3$ & $8.5 \pm 0.3$ \\
\hline Caffeine $(\mathrm{e}-$ ) & Emax & $39 \pm 3$ & $27 \pm 2^{*}$ & $27 \pm 2^{*}$ & $53 \pm 4^{*}$ & $40 \pm 4 \uparrow, \ddagger$ & $37 \pm 2 \dagger, \S$ \\
\hline
\end{tabular}

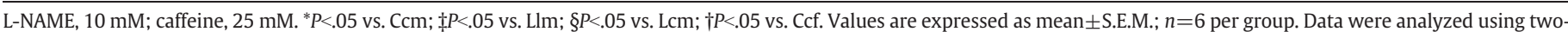
way ANOVA followed by Bonferroni post hoc test. 
$\mathbf{A}$

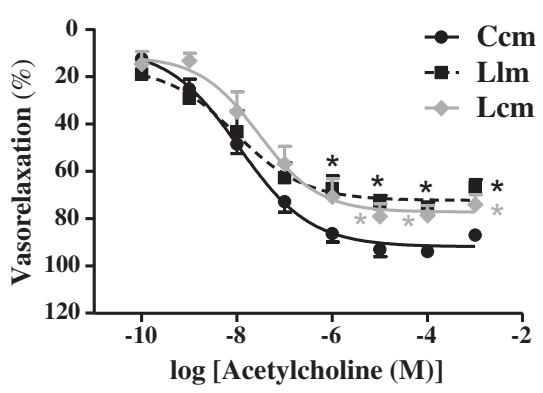

C

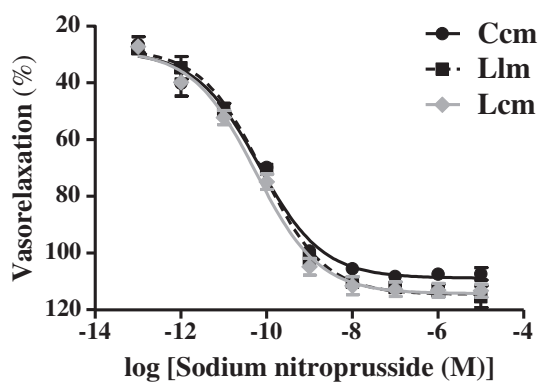

$\mathbf{E}$

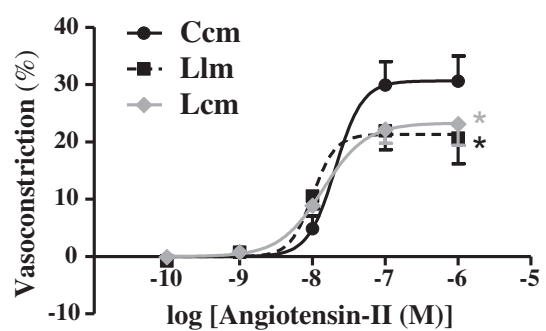

B

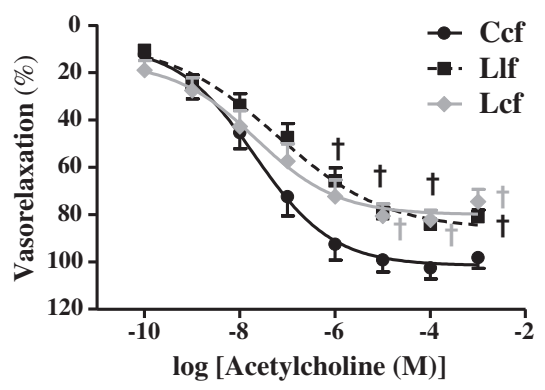

D

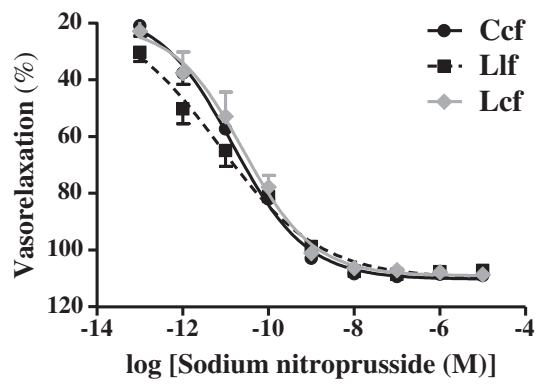

$\mathbf{F}$

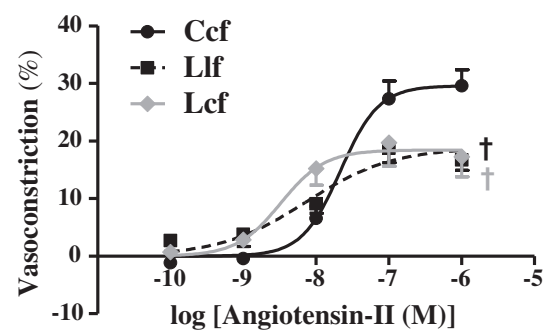

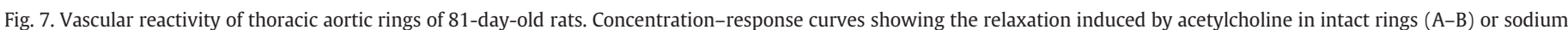

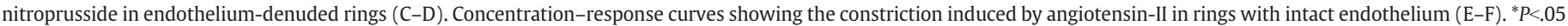
vs. Ccm; $\uparrow P<.05$ vs. Ccf. Values are expressed as mean \pm S.E.M.; $n=6-8$ per group. Data were analyzed using ANOVA followed by Bonferroni post hoc test.

Moreover, adult female rats exhibited higher eNOS activity and/or expression than males. These data suggest a higher protected status in adult females and are consistent with other studies showing that treatment with estradiol and progesterone increases eNOS-derived NO production both in isolated endothelial cells and in vascular tissue [61,62]. The protective effect of estrogens and progesterone is absent in 6-day-old rats since their gonads are not fully mature and the levels of these hormones are much lower compared with adults. This could explain absence of sex differences in NOS activity among young rats [63].

On the other hand, the redox environment greatly influences NO bioavailability. A higher production of superoxide anion could reduce NO bioavailability by generating peroxynitrites [64]. Zinc acts as an antioxidant inducing the generation of metallothioneins and cysteinerich proteins, and protecting the sulfhydryl groups of biomolecules from oxidation. It also increases the activation of antioxidant systems; decreases the activity of oxidant-promoting enzymes, such as NADPH oxidase; and inhibits lipid peroxidation production [8-10].

In our experimental model, we observed an increase in vascular oxidative stress in 6-day-old Lf and Lm rats that could contribute to reduce NO availability or to eNOS uncoupling. This increase in oxidative stress was characterized by higher lipid peroxidation in $\mathrm{Lm}$ and $\mathrm{Lf}$ and increased NADPH oxidase-dependent superoxide anion production in Lf.
However, the higher aortic oxidative stress observed in zincdeficient rats during early postnatal life was not maintained into adult life. Our results lead us to hypothesize that there is an activation of antioxidant defenses in the aortic tissue of male and female $\mathrm{Ll}$ and $\mathrm{Lc}$ rats, allowing them to maintain the levels of ROS involved in vascular superoxide anion production and in lipid peroxidation. Moreover, a compensated oxidative state would prevent an even lower availability of NO in aortic tissue. Since the distribution of zinc and the antioxidant capacity vary greatly among different tissues/organs, the impact of zinc deficiency on oxidative stress is clearly tissue dependent. In this regard, we reported similar results in cardiac tissue of zincdeficient rats. Meanwhile, higher lipid peroxidation levels and lower antioxidant enzyme activity and glutathione levels were observed in kidney $[22,56]$.

Taking into account these results, we evaluated whether zinc deficiency during different periods of growth altered vascular function in male and female offspring. In accordance with vascular NOS activity results, we observed a decrease in the endothelial dependent-vasodilator response to $\mathrm{ACh}$ in thoracic aorta rings of male and female $\mathrm{Ll}$ and Lc. The smooth muscle relaxation induced by ACh depends on NO produced in the endothelial cells. However, we did not observe significant changes in the smooth muscle relaxation response to an NO donor, like SNP, among the studied groups. These 
results suggest a preserved action of NO in smooth muscle, and a lower endothelial production or bioavailability of NO could be responsible for the lower vasodilator response to ACh. However, when evaluating vascular oxidative state, we did not observe changes in NAPDH oxidase activity or in TBARS levels in adult male or female $\mathrm{Ll}$ and Lc. Thus, it could be postulated that the lower vasodilator response to ACh observed in the $\mathrm{Ll}$ and Lc groups would be caused mainly by a decrease in NO production rather than a decrease in NO bioavailability.

Previous studies have also reported that endothelium-dependent vasorelaxation is attenuated in the vasculature of offspring of rats with different dietary manipulations $[65,66]$. It has been shown that a lowprotein diet during fetal life induces an increase in blood pressure and lower vascular eNOS activity in adult rats that is accompanied by a lower vasodilator response to ACh [66,67]. Moreover, Franco et al. reported that endothelium-intact aortic rings from adult male and female rats exposed to intrauterine undernutrition exhibited decreased vasodilation to ACh and unaltered responses to SNP in comparison with aortic rings from control rats [29].

In addition, zinc deficiency during fetal and postnatal life programmed a lower contractile response to AngII in thoracic aorta rings of adult male and female offspring even when there was a lower production of endothelial NO. The decreased vascular contractile response could be associated to different factors like changes in affinity to angiotensin receptors, in the expression of contractile proteins or in calcium availability [68]. In the present study, we observed a reduced contractile response of aortic rings to caffeine in male and female $\mathrm{Ll}$ and Lc rats, indicating a lower mobilization of calcium from the sarcoplasmic reticulum to the cytosol during smooth muscle contraction. Since no differences in aortic constriction with $\mathrm{KCl}$ were observed, the impaired AngII response could be due to alterations in intracellular calcium mobilization and not in extracellular calcium entry.

Impaired endothelial-dependent relaxant response may be a causative factor or a consequence of the elevated blood pressure. Our data show that zinc deficiency during different periods of life induces an increase in SBP in male offspring even when no sex-related differences were observed in aortic reactivity studies. Since aorta is a large-capacitance vessel that has minor participation in blood pressure regulation, future functional studies in resistant vessels would be useful to explore vascular alterations that could directly impact on blood pressure levels. Moreover, other mechanisms may be involved in the blood pressure increase in zinc-deficient rats. In this regard, we have previously reported that dietary zinc restriction during prenatal and postnatal growth impairs renal and cardiac function in adult male rats. These alterations were related to changes in apoptosis, inflammatory cytokines, growth factors expression, oxidative stress and NO system. On the other hand, females would be less sensitive to this micronutrient deficiency since they exhibited no significant structural or functional cardiac alterations and lower changes in NO system $[22,23,56]$.

Therefore, this study strengthens the importance of a balanced intake of micronutrients during prenatal and postnatal growth to ensure an adequate vascular function in adult life. In summary, our findings suggest that dietary zinc restriction during fetal life, lactation and/or postweaning growth programs lower contractile and endothelial-dependent relaxant responses in thoracic aorta of adult males and females. Some of the cellular mechanisms underlying the defective vascular relaxation may include a reduction in endothelial NO production since early periods of life, as well as changes in cytosolic calcium bioavailability during smooth muscle contraction. Moreover, an adequate zinc diet during postnatal life could not reverse the detrimental effects of this earlier micronutrient deficiency on vascular tissue. Finally, our results show sex differences in the vascular effects of this nutritional injury.

\section{Acknowledgments}

We thank Gretel Wenk, Julieta Gondolesi, Agustina Castañon, Hector Fasoli and Gabriela Noceti for technical assistance and Ana Borthwick for proofreading and language assistance.

\section{Disclosure}

The authors declare no conflict of interest.

\section{References}

[1] Amoroso L. The Second International Conference on Nutrition: implications for hidden hunger. World Rev Nutr Diet 2016;115:142-52.

[2] Wessells KR, Singh GM, Brown KH. Estimating the global prevalence of inadequate zinc intake from national food balance sheets: effects of methodological assumptions. PLoS One 2012;7(11):e50565.

[3] Alexander BT, Dasinger JH, Intapad S. Fetal programming and cardiovascular pathology. Compr Physiol 2015;5(2):997-1025.

[4] Carolan-Olah M, Duarte-Gardea M, Lechuga J. A critical review: early life nutrition and prenatal programming for adult disease. J Clin Nurs 2015;24(23-24): 3716-29.

[5] Dasinger JH, Alexander BT. Gender differences in developmental programming of cardiovascular diseases. Clin Sci (Lond) 2016;130(5):337-48.

[6] Tomat AL, Salazar FJ. Mechanisms involved in developmental programming of hypertension and renal diseases. Gender differences. Horm Mol Biol Clin Invest 2014;18(2):63-77.

[7] Spann MN, Smerling J, Gustafsson H, Foss S, Altemus M, Monk C. Deficient maternal zinc intake-but not folate-is associated with lower fetal heart rate variability. Early Hum Dev 2015;91(3):169-72.

[8] Prasad AS. Clinical, immunological, anti-inflammatory and antioxidant roles of zinc. Exp Gerontol 2008;43(5):370-7.

[9] Prasad AS. Zinc: an antioxidant and anti-inflammatory agent: role of zinc in degenerative disorders of aging. J Trace Elem Med Biol 2014;28(4):364-71.

[10] Maret W, Sandstead HH. Zinc requirements and the risks and benefits of zinc supplementation. J Trace Elem Med Biol 2006;20(1):3-18.

[11] Atochin DN, Huang PL. Endothelial nitric oxide synthase transgenic models of endothelial dysfunction. Pflugers Arch 2010;460(6):965-74

[12] Xu S, Zhou X, Yuan D, Xu Y, He P. Caveolin-1 scaffolding domain promotes leukocyte adhesion by reduced basal endothelial nitric oxide-mediated ICAM-1 phosphorylation in rat mesenteric venules. Am J Physiol Heart Circ Physiol 2013; 305(10):H1484-3

[13] Banerjee D, Mazumder S, Kumar Sinha A. Involvement of nitric oxide on calcium mobilization and arachidonic acid pathway activation during platelet aggregation with different aggregating agonists. Int J Biomed Sci 2016;12(1):25-35.

[14] Allagnat F, Haefliger JA, Lambelet M, Longchamp A, Bérard X, Mazzolai L, et al. Nitric oxide deficit drives intimal hyperplasia in mouse models of hypertension. Eur J Vasc Endovasc Surg 2016;51(5):733-42.

[15] Förstermann U, Sessa WC. Nitric oxide synthases: regulation and function. Eur Heart J 2012;33(7):829-37.

[16] Chreifi G, Li H, McInnes CR, Gibson CL, Suckling CJ, Poulos TL. Communication between the zinc and tetrahydrobiopterin binding sites in nitric oxide synthase. biochemistry 2014;53(25):4216-23.

[17] Rafikov R, Fonseca FV, Kumar S, Pardo D, Darragh C, Elms S, et al. eNOS activation and NO function: structural motifs responsible for the posttranslational control of endothelial nitric oxide synthase activity. J Endocrinol 2011;210(3):271-84.

[18] Tomat A, Elesgaray R, Zago V, Fasoli H, Fellet A, Balaszczuk AM, et al. Exposure to zinc deficiency in fetal and postnatal life determines nitric oxide system activity and arterial blood pressure levels in adult rats. Br J Nutr 2010;26:1-8.

[19] Tomat AL, Costa MA, Girgulsky LC, Veiras L, Weisstaub AR, Inserra F, et al. Zinc deficiency during growth: influence on renal function and morphology. Life Sci 2007;80:1292-302

[20] Tomat AL, Inserra F, Veiras L, Vallone MC, Balaszczuk AM, Costa MA, et al. Moderate zinc restriction during fetal and postnatal growth of rats: effects on adult arterial blood pressure and kidney. Am J Physiol Regul Integr Comp Physiol 2008;295(2):R543-

[21] Tomat AL, Weisstaub AR, Jauregui A, Piñeiro A, Balaszczuk AM, Costa MA, et al. Moderate zinc deficiency influences arterial blood pressure and vascular nitric oxide pathway in growing rats. Pediatr Res 2005;58(4):672-6.

[22] Juriol LV, Gobetto MN, Mendes Garrido Abregú F, Dasso ME, Pineda G, Güttlein L, et al. Cardiac changes in apoptosis, inflammation, oxidative stress, and nitric oxide system induced by prenatal and postnatal zinc deficiency in male and female rats. Eur J Nutr 2016:1-15. https://doi.org/10.1007/s00394-016-1343-5.

[23] Tomat AL, Juriol LV, Gobetto MN, Veiras LC, Mendes Garrido F, Zilberman J, et al. Morphological and functional effects on cardiac tissue induced by moderate zinc deficiency during prenatal and postnatal life in male and female rats. Am J Physiol Heart Circ Physiol 2013;305:H1574-83. 
[24] Franco MC, Christofalo DM, Sawaya AL, Ajzen SA, Sesso R. Effects of low birth weight in 8- to 13-year-old children: implications in endothelial function and uric acid levels. Hypertension 2006;48(1):45-50.

[25] Joo Turoni C, Chaila Z, Chahla R, Bazán de Casella MC, Peral de Bruno M. Vascular function in children with low birthweight and its relationship with early markers of cardiovascular risk. Horm Res Paediatr 2016;85(6):396-405.

[26] Purnomowati A, Kariadi SH, Achmad TH, Mose JC, Setianto B. Endothelial dysfunction in the young adult: a retrospective cohort study on the effect of low birth weight. Acta Med Indones 2014:46(2):111-6.

[27] Visentin S, Grumolato F, Nardelli GB, Di Camillo B, Grisan E, Cosmi E. Early origins of adult disease: low birth weight and vascular remodeling. Atherosclerosis 2014; 237(2):391-9.

[28] Grigore D, Ojeda NB, Alexander BT. Sex differences in the fetal programming of hypertension. Gend Med 2008;5(Suppl. A):S121-32.

[29] Franco MdoC, Arruda RM, Dantas AP, Kawamoto EM, Fortes ZB, Scavone C, et al. Intrauterine undernutrition: expression and activity of the endothelial nitric oxide synthase in male and female adult offspring. Cardiovasc Res 2002;56(1): 145-53.

[30] Ozaki T, Nishina H, Hanson MA, Poston L. Dietary restriction in pregnant rats causes gender-related hypertension and vascular dysfunction in offspring. J Physiol 2001;530(Pt 1):141-52.

[31] Reeves PG, Nielsen FH, Fahey Jr GC. AIN-93 purified diets for laboratory rodents: final report of the American Institute of Nutrition ad hoc writing committee on the reformulation of the AIN-76A rodent diet. J Nutr 1993;123(11):1939-51.

[32] Sapp RE, Davidson SD. Microwave digestion of multi-component foods for sodium analysis by atomic absorption spectrometry. J Food Sci 1991;56(5):1412-4.

[33] Ceron CS, Rizzi E, Guimaraes DA, Martins-Oliveira A, Cau SB, Ramos J, et al. Time course involvement of matrix metalloproteinases in the vascular alterations of renovascular hypertension. Matrix Biol 2012;31(4):261-70.

[34] Lemay J, Hale TM, deBlois D. Neointimal-specific induction of apoptosis by losartan results in regression of vascular lesion in rat aorta. Eur J Pharmacol 2009; 618(1-3):45-51.

[35] Salum E, Kampus P, Zilmer M, Eha J, Butlin M, Avolio AP, et al. Effect of vitamin D on aortic remodeling in streptozotocin-induced diabetes. Cardiovasc Diabetol 2012;11:58.

[36] Thent ZC, Lin TS, Das S, Zakaria Z. Histological changes in the heart and the proximal aorta in experimental diabetic rats fed with Piper sarmentsoum. Afr J Tradit Complement Altern Med 2012;9(3):396-404.

[37] Pieraggi M, Nejjar I, Julian M, Bouissou H. Staining of elastic tissue by Verhoeff's iron hematoxylin. Ann Pathol 1986;6(1):74-7.

[38] Olukman M, Sezer ED, Ulker S, Sözmen EY, Cınar GM. Fenofibrate treatment enhances antioxidant status and attenuates endothelial dysfunction in streptozotocin-induced diabetic rats. Exp Diabetes Res 2010;2010:828531.

[39] Magnani ND, Marchini T, Vanasco V, Tasat DR, Alvarez S, Evelson P. Reactive oxygen species produced by NADPH oxidase and mitochondrial dysfunction in lung after an acute exposure to residual oil fly ashes. Toxicol Appl Pharmacol 2013;270(1):31-8.

[40] Vaquero EC, Edderkaoui M, Pandol SJ, Gukovsky I, Gukovskaya AS. Reactive oxygen species produced by $\mathrm{NAD}(\mathrm{P}) \mathrm{H}$ oxidase inhibit apoptosis in pancreatic cancer cells. J Biol Chem 2004;279(33):34643-54.

[41] Romero M, Caniffi C, Bouchet G, Costa MA, Elesgaray R, Arranz C, et al. Chronic treatment with atrial natriuretic peptide in spontaneously hypertensive rats: beneficial renal effects and sex differences. PLoS One 2015;10(3):e0120362.

[42] Camm EJ, Hansell JA, Kane AD, Herrera EA, Lewis C, Wong S, et al. Partial contributions of developmental hypoxia and undernutrition to prenatal alterations in somatic growth and cardiovascular structure and function. Am J Obstet Gynecol 2010;203(5):495.e24-34.

[43] Kalea AZ, Clark K, Schuschke DA, Kristo AS, Klimis-Zacas DJ. Dietary enrichment with wild blueberries (Vaccinium angustifolium) affects the vascular reactivity in the aorta of young spontaneously hypertensive rats. J Nutr Biochem 2010;21(1):14-22.

[44] Meyer MR, Fredette NC, Barton M, Prossnitz ER. Regulation of vascular smooth muscle tone by adipose-derived contracting factor. PLoS One 2013:8(11):e79245.

[45] Wu L, Shi A, Zhu D, Bo L, Zhong Y, Wang J, et al. High sucrose intake during gestation increases angiotensin II type 1 receptor-mediated vascular contractility associated with epigenetic alterations in aged offspring rats. Peptides 2016;86:133-44.

[46] Crews JK, Murphy JG, Khalil RA. Gender differences in $\mathrm{Ca}(2+)$ entry mechanisms of vasoconstriction in Wistar-Kyoto and spontaneously hypertensive rats. Hypertension 1999;34(4 Pt 2):931-6.
[47] MacDonald RS. The role of zinc in growth and cell proliferation. J Nutr 2000;130 (5S Suppl):1500S-8S

[48] Hamza RT, Hamed AI, Sallam MT, et al. Ital J Pediatr 2012;38:21.

[49] Jurowski K, Szewczyk B, Nowak G, Piekoszewski W. Biological consequences of zinc deficiency in the pathomechanisms of selected diseases. J Biol Inorg Chem 2014;19(7):1069-79.

[50] Afridi HI, Kazi TG, Talpur FN, Kazi A, Arain SS, Arain SA, et al. Interaction between essential elements selenium and zinc with cadmium and mercury in samples from hypertensive patients. Biol Trace Elem Res 2014;160(2):185-96.

[51] Rodríguez-Rodríguez P, de Pablo AL, Condezo-Hoyos L, Martín-Cabrejas MA, Aguilera Y, Ruiz-Hurtado G, et al. Fetal undernutrition is associated with perinatal sex-dependent alterations in oxidative status. J Nutr Biochem 2015;26(12): 1650-9.

[52] Tain YL, Wu MS, Lin YJ. Sex differences in renal transcriptome and programmed hypertension in offspring exposed to prenatal dexamethasone. Steroids 2016; 115:40-6.

[53] Hayashi K, Shimizu E. Composition of connective tissues and morphometry of vascular smooth muscle in arterial wall of DOCA-salt hypertensive rats - in relation with arterial remodeling. J Biomech 2016;49(7):1225-9.

[54] McLeod DS, Baba T, Bhutto IA, Lutty GA. Co-expression of endothelial and neuronal nitric oxide synthases in the developing vasculatures of the human fetal eye. Graefes Arch Clin Exp Ophthalmol 2012;250(6):839-48.

[55] Duda DG, Fukumura D, Jain RK. Role of eNOS in neovascularization: NO for endothelial progenitor cells. Trends Mol Med 2004;10:143-5.

[56] Tomat AL, Veiras LC, Aguirre S, Fasoli H, Elesgaray R, Caniffi C, et al. Mild zinc deficiency in male and female rats: early postnatal alterations in renal nitric oxide system and morphology. Nutrition 2013;29(3):568-73.

[57] Qian J, Fulton D. Post-translational regulation of endothelial nitric oxide synthase in vascular endothelium. Front Physiol 2013;4:347.

[58] Vanhoutte PM, Zhao Y, Xu A, Leung SW. Thirty years of saying NO: sources, fate, actions, and misfortunes of the endothelium-derived vasodilator mediator. Circ Res 2016;119(2):375-96.

[59] Zhao Y, Wu J, Zhu H, Song P, Zou MH. Peroxynitrite-dependent zinc release and inactivation of guanosine 5 '-triphosphate cyclohydrolase 1 instigate its ubiquitination in diabetes. Diabetes 2013;62(12):4247-56.

[60] Ploom T, Thöny B, Yim J, Lee S, Nar H, Leimbacher W, et al. Crystallographic and kinetic investigations on the mechanism of 6-pyruvoyl tetrahydropterin synthase. J Mol Biol 1999;286(3):851-60.

[61] Pang Y, Thomas P. Additive effects of low concentrations of estradiol-17ß and progesterone on nitric oxide production by human vascular endothelial cells through shared signaling pathways. J Steroid Biochem Mol Biol 2017;165(Pt B): 258-67.

[62] Borgo MV, Claudio ER, Silva FB, Romero WG, Gouvea SA, Moysés MR, et al Hormonal therapy with estradiol and drospirenone improves endotheliumdependent vasodilation in the coronary bed of ovariectomized spontaneously hypertensive rats. Braz J Med Biol Res 2016;49(1):e4655.

[63] Jeng YJ, Kochukov M, Watson CS. Combinations of physiologic estrogens with xenoestrogens alter calcium and kinase responses, prolactin release, and membrane estrogen receptor trafficking in rat pituitary cells. Environ Health 2010;9:61.

[64] Hsieh HJ, Liu CA, Huang B, Tseng AH, Wang DL. Shear-induced endothelial mechanotransduction: the interplay between reactive oxygen species (ROS) and nitric oxide (NO) and the pathophysiological implications. J Biomed Sci 2014;21: 3.

[65] Gray C, Vickers MH, Segovia SA, Zhang XD, Reynolds CM. A maternal high fat diet programmes endothelial function and cardiovascular status in adult male offspring independent of body weight, which is reversed by maternal conjugated linoleic acid (CLA) supplementation. PLoS One 2015;10(2):e0115994.

[66] Nuyt AM. Mechanisms underlying developmental programming of elevated blood pressure and vascular dysfunction: evidence from human studies and experimental animal models. Clin Sci (Lond) 2008;114(1):1-17.

[67] Torrens C, Brawley L, Anthony FW, Dance CS, Dunn R, Jackson AA, et al. Folate supplementation during pregnancy improves offspring cardiovascular dysfunction induced by protein restriction. Hypertension 2006;47(5):982-7.

[68] Kawai T, Forrester SJ, O'Brien S, Baggett A, Rizzo V, Eguchi S. AT1 receptor signaling pathways in the cardiovascular system. Pharmacol Res 2017;125(Pt A): 4-13. 